\title{
Retraction
}

\section{Retracted: A Rare Pathological Entity of Multiple Calcified Hyperplastic Dental Follicles}

\author{
Case Reports in Dentistry \\ Received 8 February 2017; Accepted 8 February 2017; Published 30 March 2017 \\ Copyright (C) 2017 Case Reports in Dentistry. This is an open access article distributed under the Creative Commons Attribution \\ License, which permits unrestricted use, distribution, and reproduction in any medium, provided the original work is properly \\ cited.
}

At the request of the authors, the article titled "A Rare Pathological Entity of Multiple Calcified Hyperplastic Dental Follicles" [1] has been retracted. We were informed that the patient has withdrawn their consent after the article's publication. The contents of the article are no longer available online in order to protect the patient's confidentiality.

\section{References}

[1] S. Gunawardane and K. Kapugama, "A rare pathological entity of multiple calcified hyperplastic dental follicles," Case Reports in Dentistry, vol. 2016, Article ID 4190827, 3 pages, 2016. 
Case Report

\section{A Rare Pathological Entity of Multiple Calcified Hyperplastic Dental Follicles}

\section{Sumith Gunawardane and Kanchana Kapugama}

Department of Oral and Maxillofacial Surgery, Faculty of Dental Sciences, University of Peradeniya, Peradeniya, Sri Lanka

Correspondence should be addressed to Sumith Gunawardane; sumithgunawardane7@gmail.com

Received 9 November 2016; Accepted 12 December 2016

Academic Editor: Luis M. J. Gutierrez

Copyright (c) 2016 S. Gunawardane and K. Kapugama. This is an open access article distributed under the Creative Commons Attribution License, which permits unrestricted use, distribution, and reproduction in any medium, provided the original work is properly cited.

At the request of the authors, this article has been retracted. We were informed that the patient has withdrawn their consent after the article's publication. The contents of the article are no longer available online in order to protect the patient's confidentiality. 


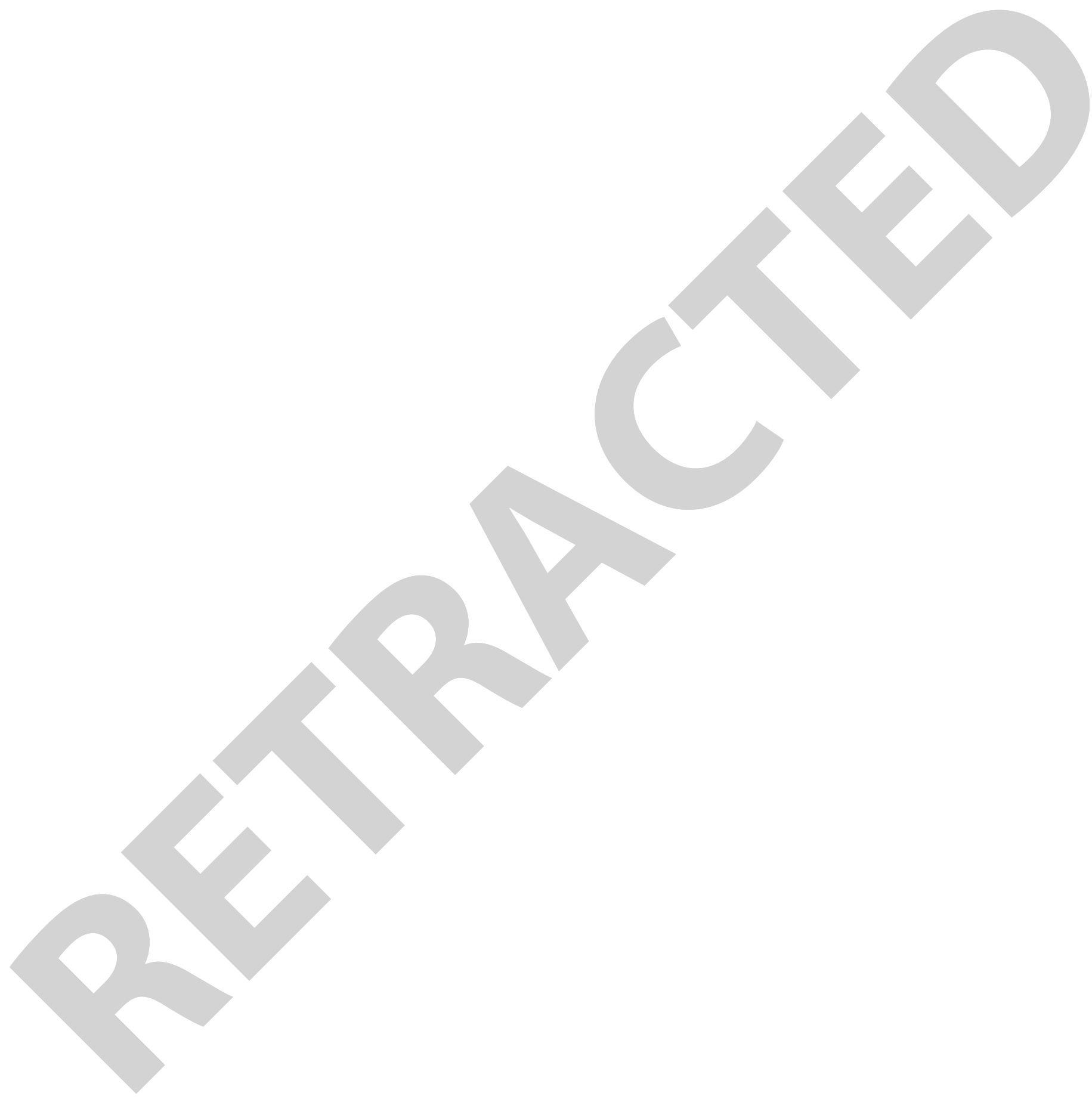


